\title{
Ribosomal Proteins and their Extra Ribosomal Functions in Abiotic Stress Tolerance of Plants
}

\author{
Moin Mazahar ${ }^{1}$, Bakshi Achala ${ }^{1}$, Saha Anusree ${ }^{2}$ and Kirti PB ${ }^{3}$ \\ ${ }^{1}$ Department of Biotechnology, Indian Institute of Rice Research, India \\ ${ }^{2}$ Department of Plant Sciences, University of Hyderabad, India \\ ${ }^{3}$ Rajendra Prasad Central Agricultural University and Agri Biotech Foundation, India
}

ISSN: 2637-7659

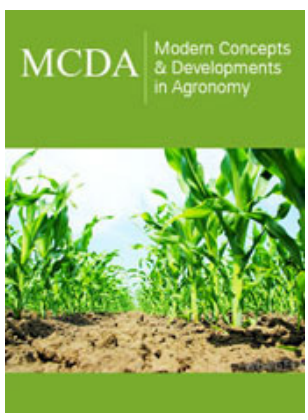

${ }^{*}$ Corresponding author: Kirti PB, Rajendraprasad Central Agricultural University, Pusa-Samasthipur-848125, Bihar and Agri Biotech Foundation, Rajendranagar, Hyderabad-500030, Telangana, India

Submission: 眥 June04, 2019

Published: 眥June 13, 2019

Volume 4 - Issue 4

How to cite this article: Mazahar M, Achala B, Anusree S, Kirti P. Plant Ribosomal Proteins and their Extra Ribosomal Functions in Abiotic Stress Tolerance. Mod Concep Dev Agrono.4(4). MCDA.000591.2019.

DOI: 10.31031/MCDA.2019.04.000591

Copyright@ Kirti PB, This article is distributed under the terms of the Creative Commons Attribution 4.0 International License, which permits unrestricted use and redistribution provided that the original author and source are credited.

\section{Opinion}

Ribosomal proteins (RPs) that include both small (RPS) and large subunit (RPL) proteins have been known to be involved in several very important functions in ribosome assembly, protein synthesis and other basic cellular functions in association with several other components [1]. The composition of ribosomal protein subunits that are involved in ribosome assembly is heterogeneous [2] indicating clearly that individual subunit protein components have other functions apart from the basic cellular functions they are associated with. Although each RP gene has multiple paralogs, the expression of all of them appears to be differentially regulated for normal development with some of them functioning in spatio-temporal and signal-induced manner while others exhibit binding properties. The expression of ribosomal proteins has been shown to be regulated by various environmental cues and treatments with signaling molecules $[3,4]$. The involvement of ribosomal proteins in extra ribosomal functions in animal systems has also been well documented [5].

The extra ribosomal functions of RPs in plants have also started coming to the fore in environmental stresses [6,7]. Several RPL and RPS genes are upregulated in rice at an early stage under salt stress [8]. A mutation in RPL24, which is an important translation initiation factor resulted in defective gynoecium development, reduced ovary size and elongated gynophore in the pistils of Arabidopsis [9]. Thus, the roles of Ribosomal Proteins in extra ribosomal functions are being slowly appreciated in plants. Water use efficiency (WUE) is an agronomically important trait in rice as it is well known that this crop requires large quantities of water to sustain its yield and productivity. It is also a well-known fact that this crop receives maximum attention in terms of allocation of water for its cultivation leaving the other crops thronging for optimal water supplies. Water saved in rice cultivation through enhanced water use efficiency can be reallocated to other crops for enhancing their productivity limits, which is important for food sustainability. In this direction, an activation tagged rice mutant population was developed and screened for identification of activation tagged mutants for enhanced water use efficiency and this analysis has revealed that two out of the five potential mutants that exhibited enhanced water use efficiency as estimated using $\triangle^{13} \mathrm{C}$ analysis demonstrated the activation of two ribosomal protein large subunit genes, RPL6 and RPL23A associated with significantly enhanced water use efficiency [10]. Subsequent interesting analyses by Moin et al. [4] and Saha et al. [11] in a genome wide survey and characterization of RPL and RPS genes in rice showed that these genes are differentially regulated in various abiotic and biotic stress treatments and in response to the treatments with different signaling molecules. These analyses also validated the differential expression of RPL6 and RPL23A identified in the activation tagging experiments on rice water use efficiency. The involvement of RPL23A in abiotic stress tolerance was further demonstrated by its constitutive overexpression in the native system, rice [12]. The ribosomal proteins also appear to be under the modulatory control of a Serine/ Threonine Protein Kinase-the Target of Rapamycin (TOR). It has been demonstrated that one of the downstream targets of TOR is another kinase, p70 kDa, S6 kinase1 (S6K1), which phosphorylates the Ribosomal Protein Small Subunit, RPS6 [13] for translational activation in eliciting a cascade of signaling events ensuring plant development and survival. 
TOR inactivation resulted in reduced growth and ribosome biogenesis by coordinated downregulation of transcription and translation of plastidic ribosomal proteins and rRNA in Arabidopsis plants [14-16]. Ectopic overexpression of Arabidopsis thaliana TOR in rice was also associated with significantly enhanced expression of the Ribosomal Protein genes, which was also associated with enhanced water use efficiency and high photosynthetic efficiency [17] corroborating the earlier observations on enhanced expression of RP genes in stress conditions. All these findings provided a secure basis for the extra-ribosomal activities of RPs. The targeted overexpression of selected RP genes can be exploited in crop systems to ameliorate abiotic stress and improve plant performance. However, the important link between TOR activity, RP phosphorylation, ribosome biogenesis and translation efficiency to impact protein synthesis under environmental stresses in plants has not yet been properly elucidated. In essence, the ribosomal proteins are also involved in extra ribosomal functions in addition to the routine basic housekeeping functions in the cell. The literature on their extra ribosomal functions is slowly accumulating in various systems including plants. To comprehensively summarize the extra ribosomal functions of the Ribosomal Proteins in various systems, a special issue has been launched on the Journal "Frontiers in Bioscience", which is scheduled for the year 2021 and contributions in all formats are welcome for inclusion in that issue.

\section{References}

1. Maguire BA, Zimmermann R A (2001) The ribosome in focus. Cell 104(6): 813-816.

2. Doudna JA, Rath VL (2002) Structure and function of the eukaryotic ribosome: The next frontier. Cell 109(2): 153-156.

3. Hulm JL, McIntosh KB, Bonham Smith PC (2005) Variation in transcript abundance among the four members of the Arabidopsis thaliana RIBOSOMAL PROTEIN S15a gene family. Plant Science 169(1): 267-278.

4. Moin M, Bakshi A, Saha A, Datta M, Madhav MS, et al. (2016b) Rice ribosomal protein large subunit genes and their spatio-temporal and stress regulation. Front Plant Sci 7: 1284.

5. Warner J R, McIntosh K B (2009) How common are extra ribosomal functions of ribosomal proteins? Mol Cell 34(1): 3-11.

6. Sormani, R, Daubresse MC, Vedele DF, Chardon F (2011) Transcriptional regulation of ribosome components are determined by stress according to cellular compartments in Arabidopsis thaliana. PLoS ONE 6(12): e28070.

7. Hummel M, Cordewener JH, DeGroot J, Smeekens S, America AH, et al. (2012) Dynamic protein composition of Arabidopsis thaliana cytosolic ribosomes in response to sucrose feeding as revealed by label free MSE proteomics. Proteomics 12(7): 1024-1038.

8. Kawasaki S, Borchert C, Deyholos M, Wang H, Brazille S, et al. (2001) Gene expression profiles during the initial phase of salt stress in rice. Plant Cell 13(4): 889-905.

9. Nishimura T, Wada T, Okada K (2004) A key factor of translation reinitiation, ribosomal protein $\mathrm{L} 24$ is involved in gynoecium development in Arabidopsis. Biochem Soc Trans 32(Pt 4): 611-613.

10. Moin M, Bakshi A, Saha A, Udaya Kumar M, Reddy AR, et al. (2016a) Activation tagging in indica rice identifies ribosomal proteins as potential targets for manipulation of water-use efficiency and abiotic stress tolerance in plants. Plant Cell Environ 39(11): 2440-2459.

11. Saha A, Das S, Moin M, Dutta M, Bakshi A, et al. (2017) Genome-Wide identification and comprehensive expression profiling of Ribosomal Protein Small Subunit (RPS) genes and their comparative analysis with the Large Subunit (RPL) Genes in rice. Front Plant Sci 8:1553.

12. Moin M, Bakshi A, Madhav MS, Kirti PB (2017) Expression profiling of Ribosomal Protein gene family in dehydration stress responses and characterization of transgenic rice plants overexpressing RPL23A for water-use efficiency and tolerance to drought and salt stresses. Front Chem 5: 97.

13. Xiong Y, Sheen J (2015) Novel links in the plant TOR kinase signaling network. Curr Opin Plant Biol 28: 83-91.

14. Deprost D, Yao L, Sormani R, Moreau M, Leterreux G, et al. (2007) The Arabidopsis TOR kinase links plant growth, yield, stress resistance and mRNA translation. EMBO Reports 8(9): 864-870.

15. Ren M, Qiu S, Venglat P, Xiang D, Feng L, et al. (2011) Target of rapamycin regulates development and ribosomal RNA expression through kinase domain in Arabidopsis. Plant Physiol 155(3): 1367-1382.

16. Dobrenel T, Martínez ME, Forzani C, Azzopardi M, Davanture M, et al. (2016) The Arabidopsis TOR kinase specifically regulates the expression of nuclear genes coding for Plastidic ribosomal proteins and the phosphorylation of the cytosolic ribosomal protein S6. Front Plant Sci 7: 1611.

17. Bakshi A, Moin M, Udaya Kumar M, Ren M, Datla R, et al. (2017) Ectopic expression of Arabidopsis target of Rapamycin (AtTOR) improves wateruse-efficiency and yield potential in rice. Sci Rep 7: 42835 . 